\title{
RANCANG BANGUN APLIKASI KOPERASI SIMPAN PINJAM MENGGUNAKAN METODE RESEARCH AND DEVELOPMENT
}

\author{
Matheus Supriyanto Rumetna \\ Fakultas Ilmu Komputer, Program Studi Sistem Informasi \\ Universitas Victory Sorong \\ Email: matheus.rumetna@gmail.com \\ Tirsa Ninia Lina \\ Fakultas Ilmu Komputer, Program Studi Sistem Informasi \\ Universitas Victory Sorong \\ Email: tirsawp@gmail.com \\ Agustinus Budi Santoso \\ Program Studi Desain Grafis \\ STEKOM Semarang \\ Email: agustinus.bs@stekom.ac.id
}

\begin{abstract}
ABSTRAK
Usaha koperasi simpan pinjam $\mathrm{ABC}$ merupakan usaha yang bergerak di bidang jasa, dimana usaha ini sering mengalami masalah tentang perekapan data yaitu pencatatan transaksi karena human-error. Usaha ini dapat mengandalkan perangkat lunak atau aplikasi dalam kegiatan kerja sehari-hari agar lebih mudah dalam melakukan pengolahan atau manajemen data, baik data anggota, data pembayaran cicilan kredit hingga rekapan laporan usaha. Sehingga meminimalisir human-error serta meningkatkan kinerja koperasi simpan pinjam karena semua pencatatan transaksi dilakukan melalui aplikasi. Aplikasi ini dibangun menggunakan metode Research And Development (R\&D) serta perancangannya menggunakan Unified Modelling Language (UML). Hasilnya adalah aplikasi ini dapat mengelola data dengan baik, mulai dari data anggota, data setoran, data pengambilan, data peminjaman, data pembayaran cicilan serta dapat menampilkan rekapan laporan usaha sehingga data-data tersebut menjadi informasi yang bermanfaat. Pengujian yang dilakukan terhadap aplikasi ini menggunakan Black Box Testing, dimana setiap fungsi yang ada berjalan dengan baik (valid).
\end{abstract}

Kata kunci: aplikasi; koperasi; research and development.

\section{ABSTRACT}

$A B C$ savings and loan cooperative is a business engaged in services, where these businesses often experience problems regarding the recapitulation of data, namely recording transactions due to humanerror. This business can rely on software or applications in daily work activities to make it easier to do data processing or management, both member data, credit installment payment data and business report recapitulation. So as to minimize human error and improve the performance of savings and loan cooperatives because all recording of transactions is done through the application. This application was built using the Research And Development ( $R \& D)$ method and its design using the Unified Modeling Language (UML). The result is that this application can manage data well, starting from member data, deposit data, retrieval data, loan data, installment payment data and can display business report recapitations so that the data becomes useful information. Tests performed on this application using the Black Box Testing, where every function is running well (valid).

Keywords: application; cooperative; research and development.

\section{PENDAHULUAN}

Teknologi Informasi dan Komunikasi (TIK) saat ini telah menjadi alat bantu utama bagi manusia juga diadopsi oleh beragam aspek kehidupan, kondisi ini terjadi karena TIK dapat berkolaborasi dengan banyak bidang pengetahuan. Bagi organisasi swasta maupun pemerintah, TIK telah membawa perubahan yang fundamental sehingga menjadi suatu backbone utama untuk banyak sektor (1).

Semua aktifitas yang dilakukan manusia dapat dikerjakan dengan memanfaatkan TIK. Bukan hanya untuk mengetik dan bermain game, tetapi dapat juga digunakan untuk mencari informasi yang dibutuhkan secara cepat, tepat, dan akurat. Salah satu hal yang paling sering terjadi sekarang ini dalam lingkungan kerja adalah bagaimana 
TIK digunakan untuk membantu proses kerja sehari-hari, contohnya dalam usaha koperasi. Hal ini mendorong manusia untuk membuat aplikasi yang dapat membantu dalam melaksanakan usaha tersebut (2).

Koperasi berasal dari kata coopere atau cooperation yang artinya Co bersama dan operation bekerjasama, sehingga jika digabung memiliki arti yaitu bekerjasama. Atau dapat dikatakan koperasi berarti menolong satu sama lain karena kerja sama yang dilakukan memiliki maksud untuk kepentingan dan tujuan yang sejalan dari orangorang yang ada didalam koperasi (3).

Koperasi juga merupakan organisasi ekonomi rakyat yang dapat memajukan kesejahteraan rakyat juga ikut membangun tatanan pereknomian nasional guna mewujudkan masyarakat yang adil, maju serta makmur, hal ini berdasarkan Pancasila dan Undang-Undang nomor 25 tahun 1992. Hal penting lainnya ialah koperasi adalah penggerak ekonomi rakyat yang berdasarkan asas kekeluargaan (4).

Rahma (5) dalam penelitiannya mengenai sistem informasi koperasi simpan pinjam berbasis syariah, menemukan permasalahan terkait proses pengolahan data yang masih dilakukan dengan cara semi-manual (menggunakan tulis tangan dan komputer). Proses transaksi simpanan dan pembiayaan dicatat manual pada lembar kerja dan di buku tabungan yang dibawa anggota. Catatan transaksi tersebut kemudian direkap pada komputer dengan bantuan aplikasi Microsoft Office Excel. Proses yang dilakukan membutuhkan waktu yang cukup lama dan dianggap kurang efisien, karena dapat menimbulkan terjadinya human-error.

Penelitian ini membahas tentang usaha koperasi simpan pinjam $\mathrm{ABC}$, dimana usaha ini sering mengalami masalah tentang perekapan data yaitu pencatatan transaksi karena human-error. Masalah ini dapat teratasi dengan mengandalkan TIK, dimana semua perekapan data dapat disimpan dalam suatu database dan dikelola dengan menggunakan aplikasi yang sangat efisien dan efektif dalam keberlangsungan usaha.

Usaha koperasi simpan pinjam $\mathrm{ABC}$ harus mengandalkan perangkat lunak atau aplikasi dalam kegiatan kerja sehari-hari agar lebih mudah dalam melakukan pengolahan atau manajemen data, baik data anggota maupun data pembayaran cicilan kredit (6). Data yang dikelola dengan baik, akan memiliki struktur dan atribut sehingga dapat membantu kegiatan usaha koperasi simpan pinjam, sehingga meminimalisir human-error serta meningkatkan kinerja koperasi simpan pinjam karena semua pencatatan transaksi dilakukan melalui aplikasi.

Penggunaan metode pengembangan sistem yang tepat dalam penelitian ini yaitu metode Research And Development (R\&D), dimana dengan metode ini dapat menghasilkan suatu produk, dan menguji keefektifan produk tersebut. Selain itu, metode ini juga bertujuan untuk menemukan, mengembangkan serta memvalidasi suatu produk (7). Sehingga hasil akhir dari produk (aplikasi) yang dibuat benar-benar tervalidasi dengan baik serta efektif untuk digunakan oleh pihak koperasi simpan pinjam ABC.

\section{METODOLOGI PENELITIAN}

\subsection{Teknik Pengumpulan Data} data.

Observasi, wawancara dan studi pustaka merupakan teknik yang digunakan untuk pengumpulan

a. Observasi dilakukan untuk mengamati secara langsung bagaimana proses manual yang terjadi dalam usaha koperasi simpan pinjam ABC, sehingga membantu dalam hal pembuatan aplikasi.

b. Wawancara dilakukan dengan pihak koperasi simpan pinjam $\mathrm{ABC}$ untuk mengetahui kebutuhan user, sehingga aplikasi yang dibuat sesuai dengan kebutuhan di lapangan.

c. Buku, internet, serta jurnal ilmiah mengenai aplikasi koperasi simpan pinjam merupakan sumber studi pustaka dalam penelitian ini.

\subsection{Metode Research and Development (R\&D)}

Metode R\&D digunakan dalam penelitian untuk pengembangan sistem. Adapaun tahapan metode R\&D (7) adalah sebagai berikut:

a. Research and information collecting

Tahap pertama dalam penelitian ini dilakukan dengan mengumpulkan informasi berupa permasalahan dan kebutuhan yang dihadapi.

b. Planning

Tahap kedua yaitu penyusunan rencana penelitian dilakukan untuk menentukan apa saja yang akan dikerjakan hingga akhir penelitian, menentukan tujuan yang akan dicapai.

c. Develope preliminary form of product

Tahap ketiga dilakukan dengan mempersiapkan komponen dan data pendukung dalam pembuatan aplikasi.

d. Preliminary field testing

Tahap keempat melakukan uji coba program dalam skala yang terbatas.

e. Main product revision

Tahap kelima yaitu melakukan perbaikan terhadap aplikasi yang dihasilkan berdasarkan hasil uji coba pada tahap sebelumnya. 
Perbaikan ini juga dapat dilakukan berdasarkan masukkan dari tempat penelitian, sehingga diperoleh draft produk yang siap diuji coba lebih luas.

f. Main field testing

Tahap keenam merupakan tahap akhir uji coba utama yang dilakukan berdasarkan hasil revisi yang didapatkan dari uji coba awal pada tahap keempat sebelumnya. Hasil yang diperoleh dari ujicoba ini dalam bentuk evaluasi terhadap pencapaian hasil uji coba yaitu hasil dari aplikasi.

\section{HASIL DAN PEMBAHASAN}

Aplikasi yang dibangun ini dimulai dari model kebutuhan, rekayasa desain, desain interface, desain komponen, desain deployment hingga pengujian aplikasi (2)(5)(8)(9)(10).

\subsection{Model Kebutuhan}

Model kebutuhan dalam pembuatan aplikasi ini yaitu use case diagram dan activity diagram.

a. Use Case Diagram

Use case diagram pada Gambar 1 menjelaskan bahwa pada aplikasi yang dibangun dapat digunakan oleh customer (anggota koperasi) dan admininistrator (admin). Admin merupakan aktor yang dapat mengelola data anggota, kelola data simpanan, kelola data pinjaman, kelola data pengambilan simpanan serta mengelola data angsuran anggota. Sedangkan aktor anggota dapat melakukan pendaftaran, melakukan proses simpan/pinjam, pengambilan simpanan serta melakukan pembayaran angsuran.

b. Activity Diagram

Gambar 2, menjelaskan tentang aktifitas dari masing-masing aktor yang terjadi dalam aplikasi. Dimana anggota harus melakukan pendaftaran sebelum dapat mengakses menu simpan/pinjam, menu pengambilan simpanan serta pembayaran angsuran. Sedangkan admin dapat mengakses menu kelola anggota, kelola simpanan, kelola pinjaman, kelola pengambilan simpanan serta angsuran. Yang dimaksudkan dengan kelola disini ialah admin dapat melakukan aktifitas mulai dari menambah, mengubah, sampai menghapus data.

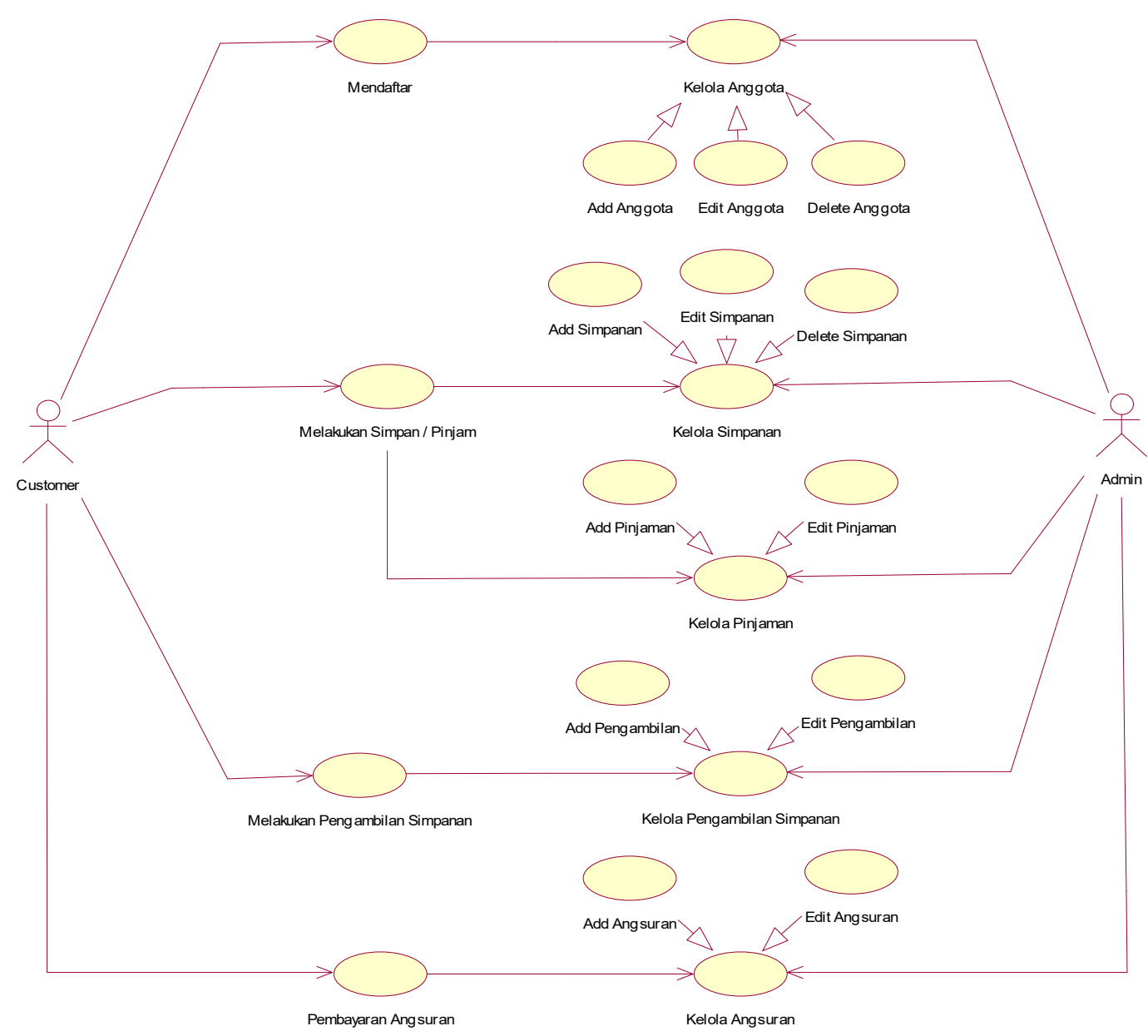

Gambar 1. Use Case Diagram 


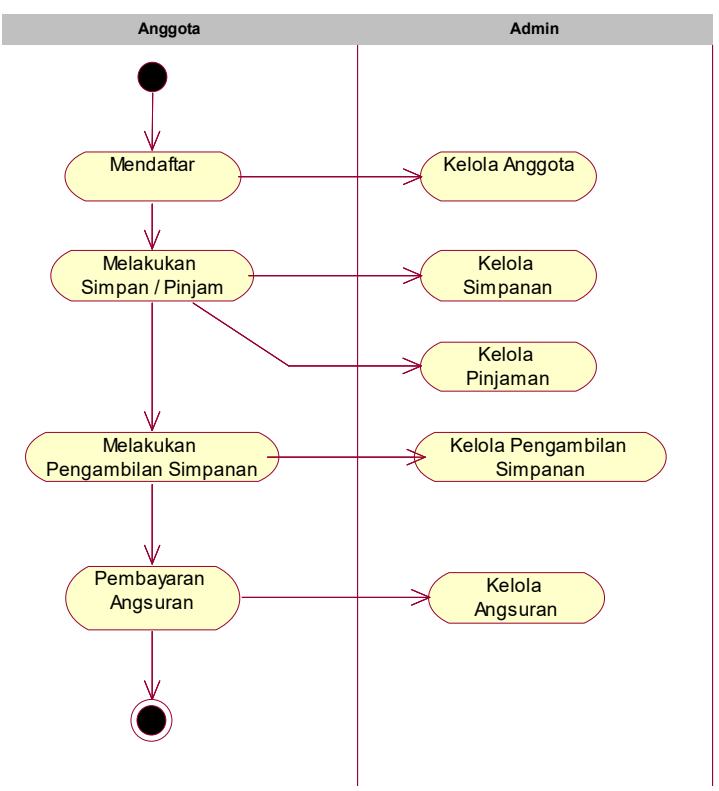

Gambar 2. Activity Diagram

\subsection{Rekayasa Desain}

Rekayasa desain menggunakan desain arsitektur dan desain data.

a. Desain Arsitektur

Gambar 3, menjelaskan desain arsitektur yang ada pada aplikasi mulai dari interface, controller hingga database.

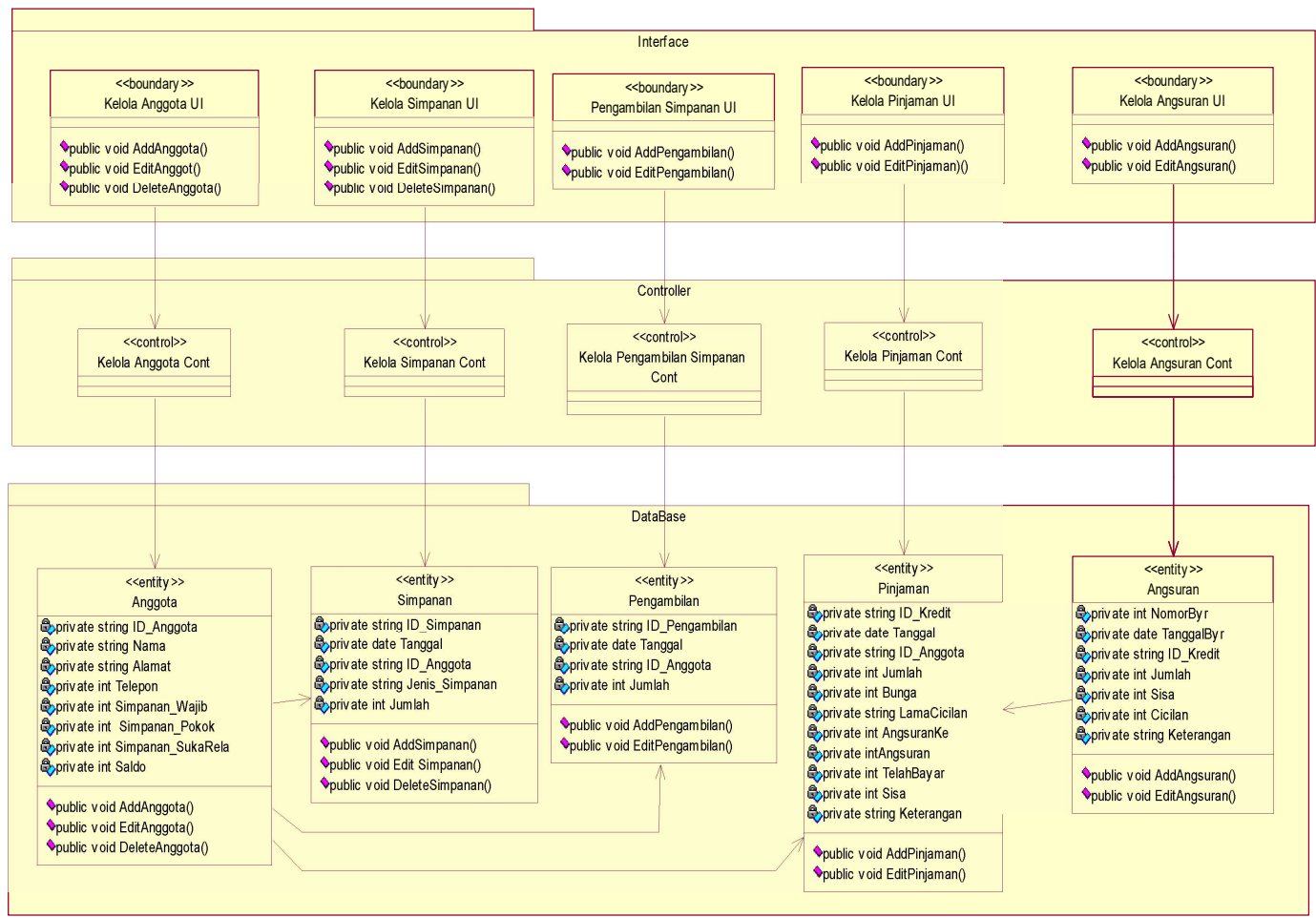

Gambar 3. Desain Arsitektur Aplikasi Koperasi Simpan Pinjam

b. Desain Data

Desain data pada Gambar 4 menjelaskan koneksi antara data yang ada pada database. 


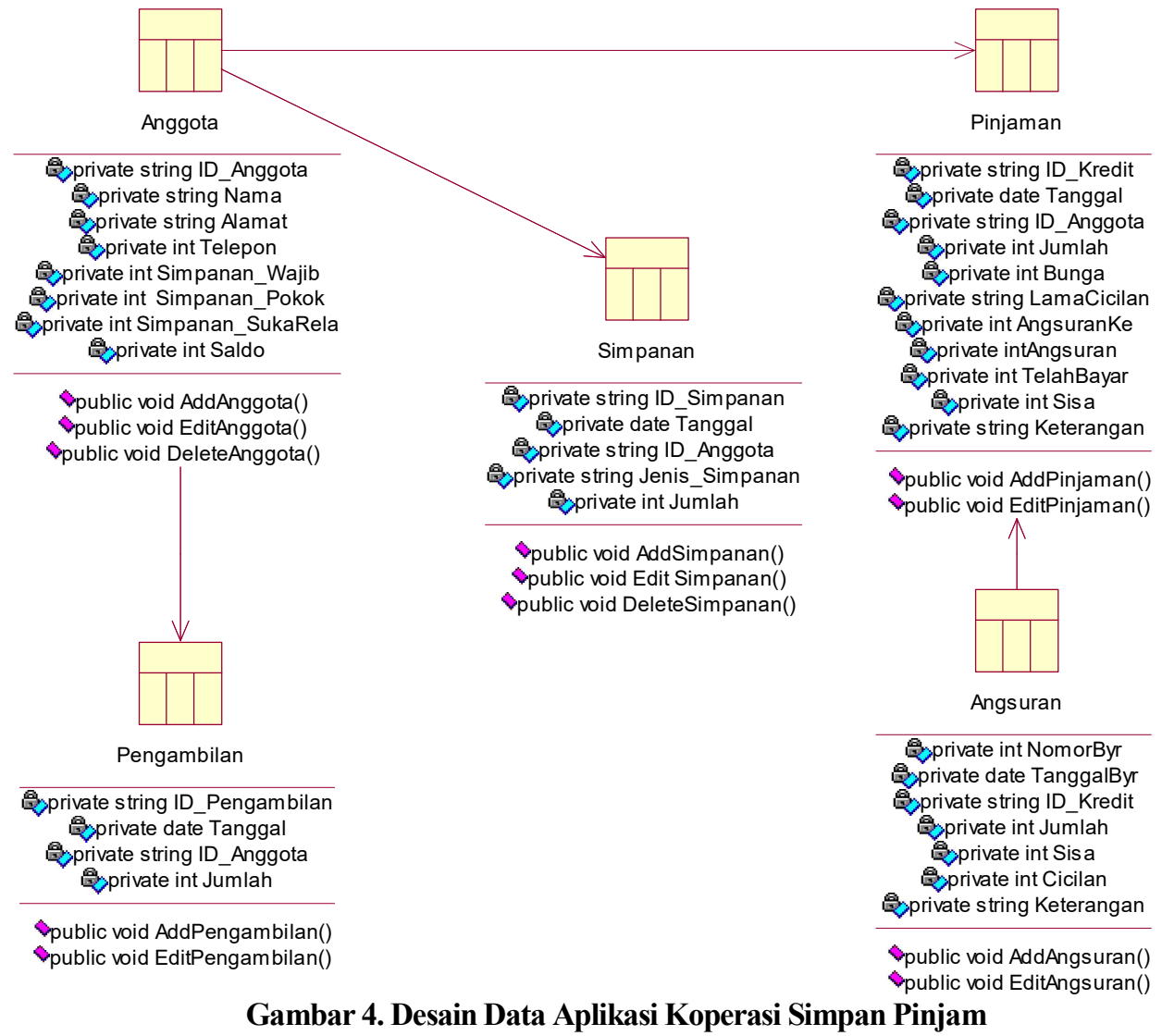

\subsection{Desain Interface}

Interface yang ada pada aplikasi ini dapat dilihat pada gambar berikut:

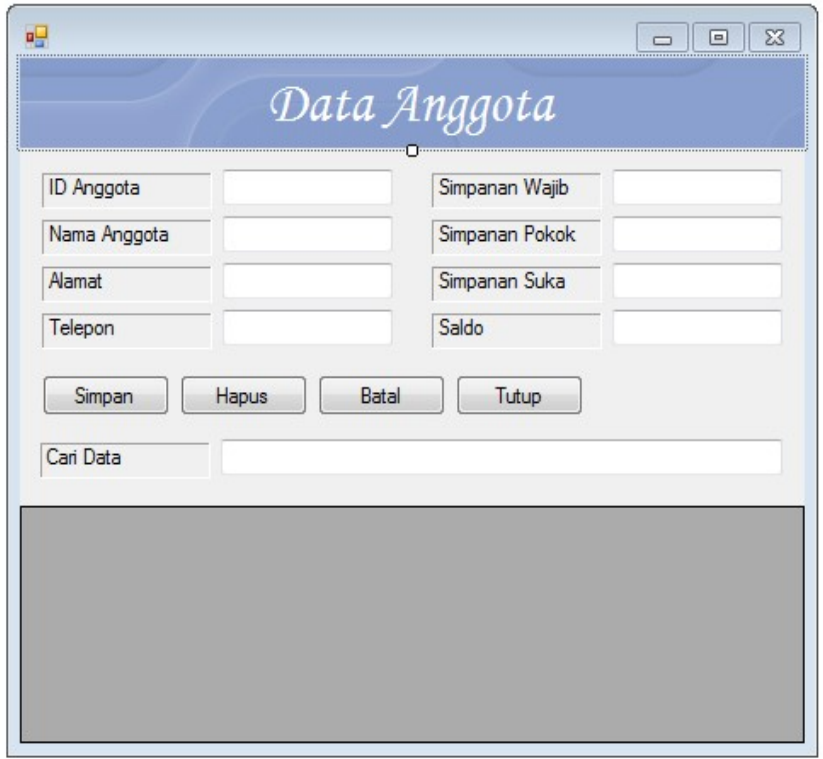

Gambar 5. Form Pendaftaran Anggota

Gambar 5, menunjukan bahwa admin dapat melakukan akses data anggota melalui form ini. 


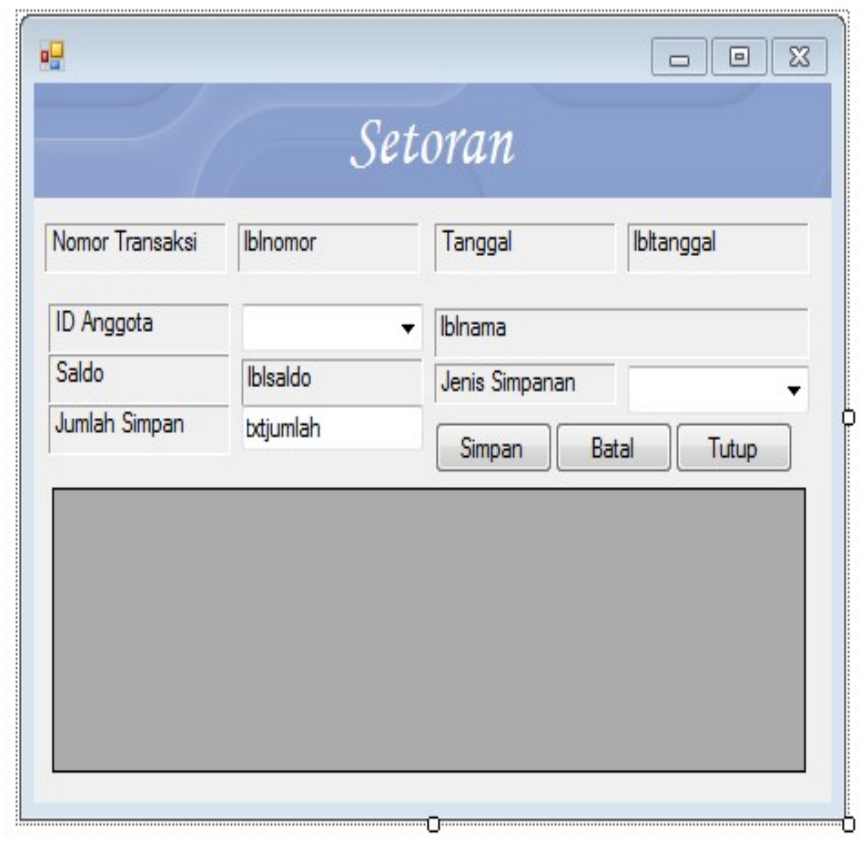

Gambar 6. Form Simpanan atau Setoran

Gambar 6, merupaka form yang digunakan untuk melihat data simpanan atau setoran yang dimiliki oleh anggota.

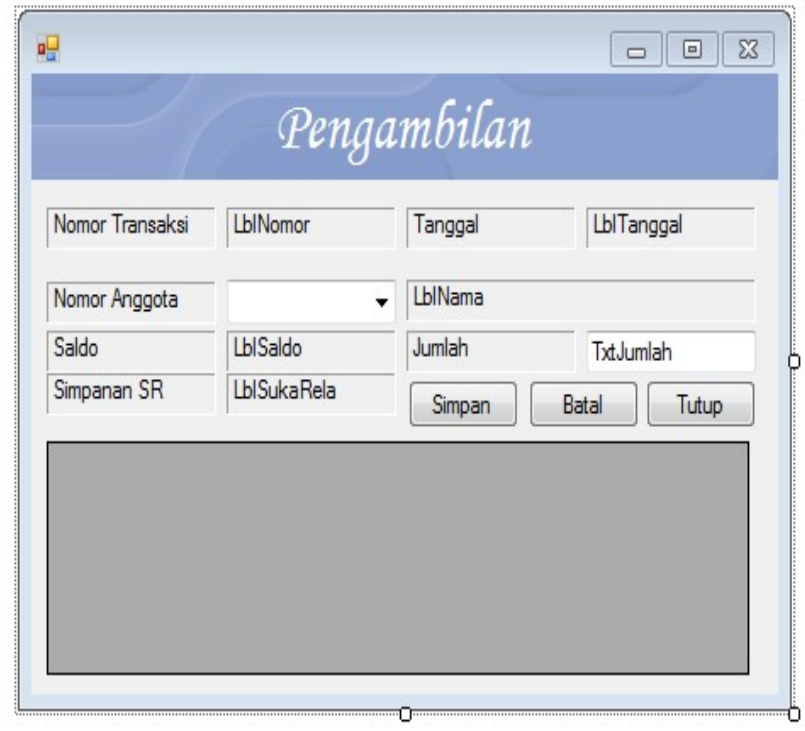

Gambar 7. Form Pengambilan

Gambar 7, merupakan form yang berfungsi untuk melihat data pengambilan anggota koperasi. 


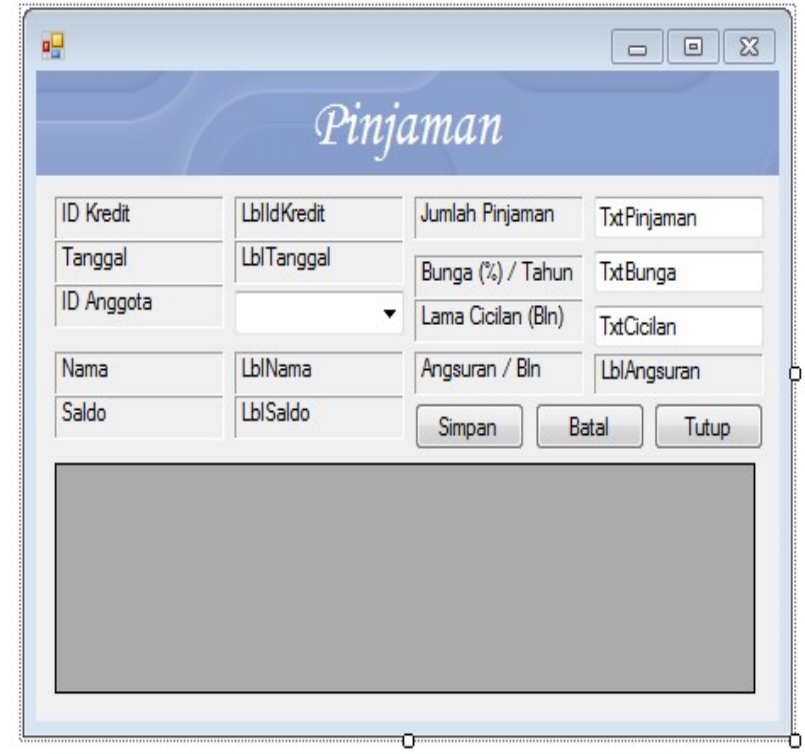

Gambar 8. Form Pinjaman

Gambar 8, merupakan form yang berfungsi untuk mencari dan melihat data pinjaman anggota koperasi.

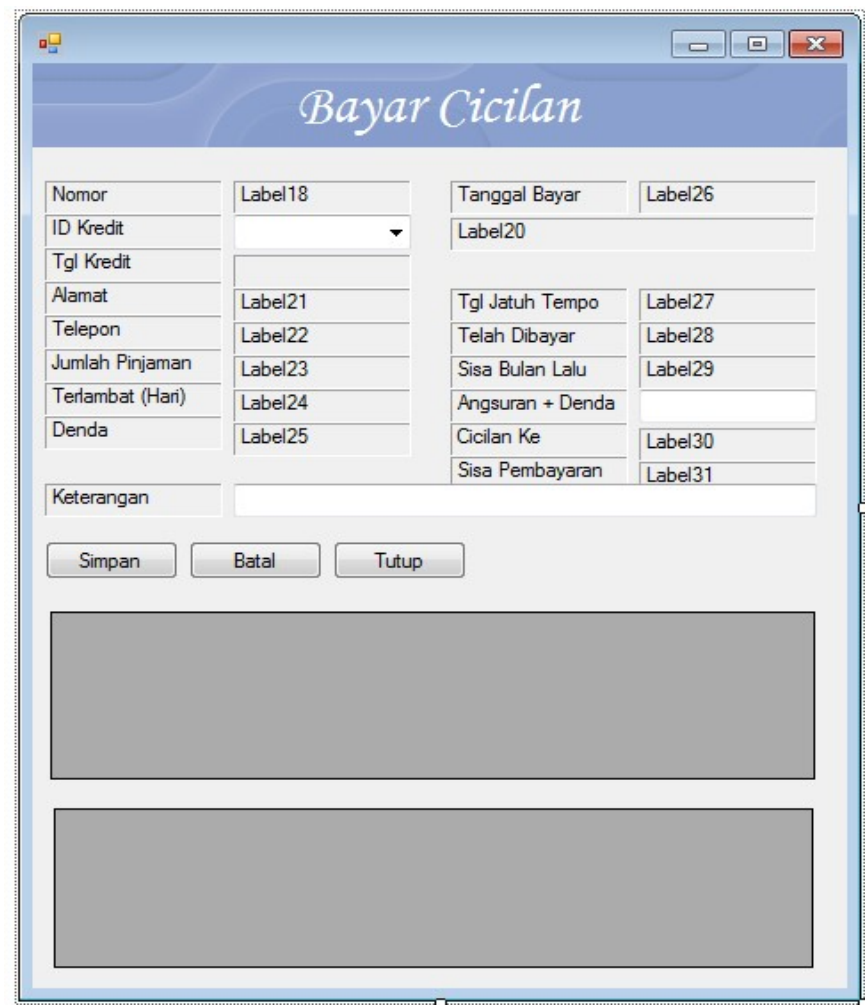

Gambar 9. Form Pembayaran Cicilan

Gambar 9, adalah form yang digunakan untuk melakukan pembayaran cicilan anggota koperasi. 


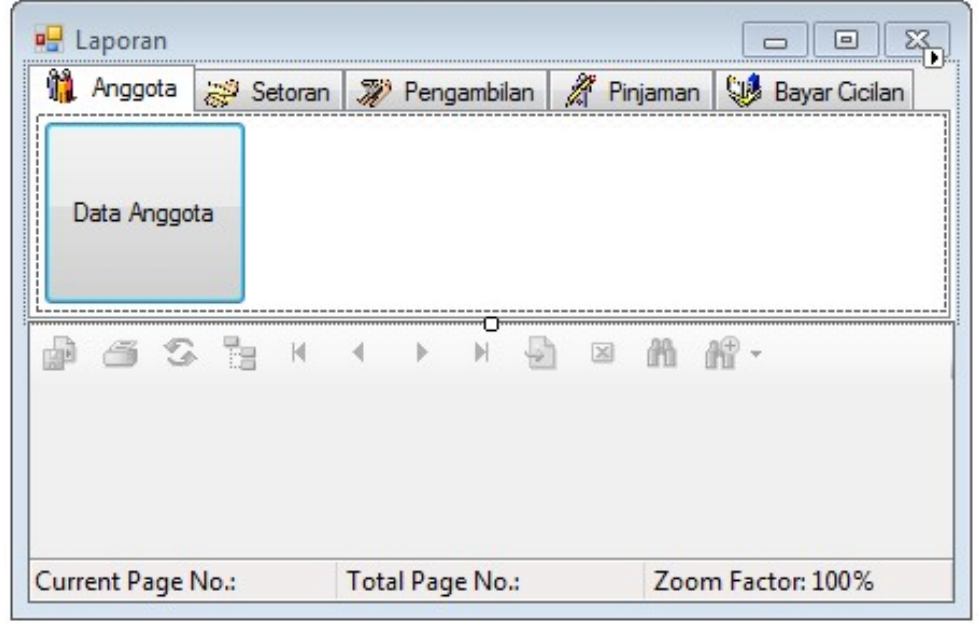

Gambar 10. Form Laporan

Gambar 10, merupakan form yang digunakan untuk menampilkan rekapan data atau laporan. Laporan yang dapat dilihat pada form ini mulai dari laporan anggota, setoran, pengambilan, pinjaman hingga pembayaran cicilan yang dilakukan oleh anggota.

\subsection{Desain Komponen}

Desain komponen digunakan untuk melihat komponen yang ada dalam database. Lebih jelasnya dapat dilihat pada Gambar 11.

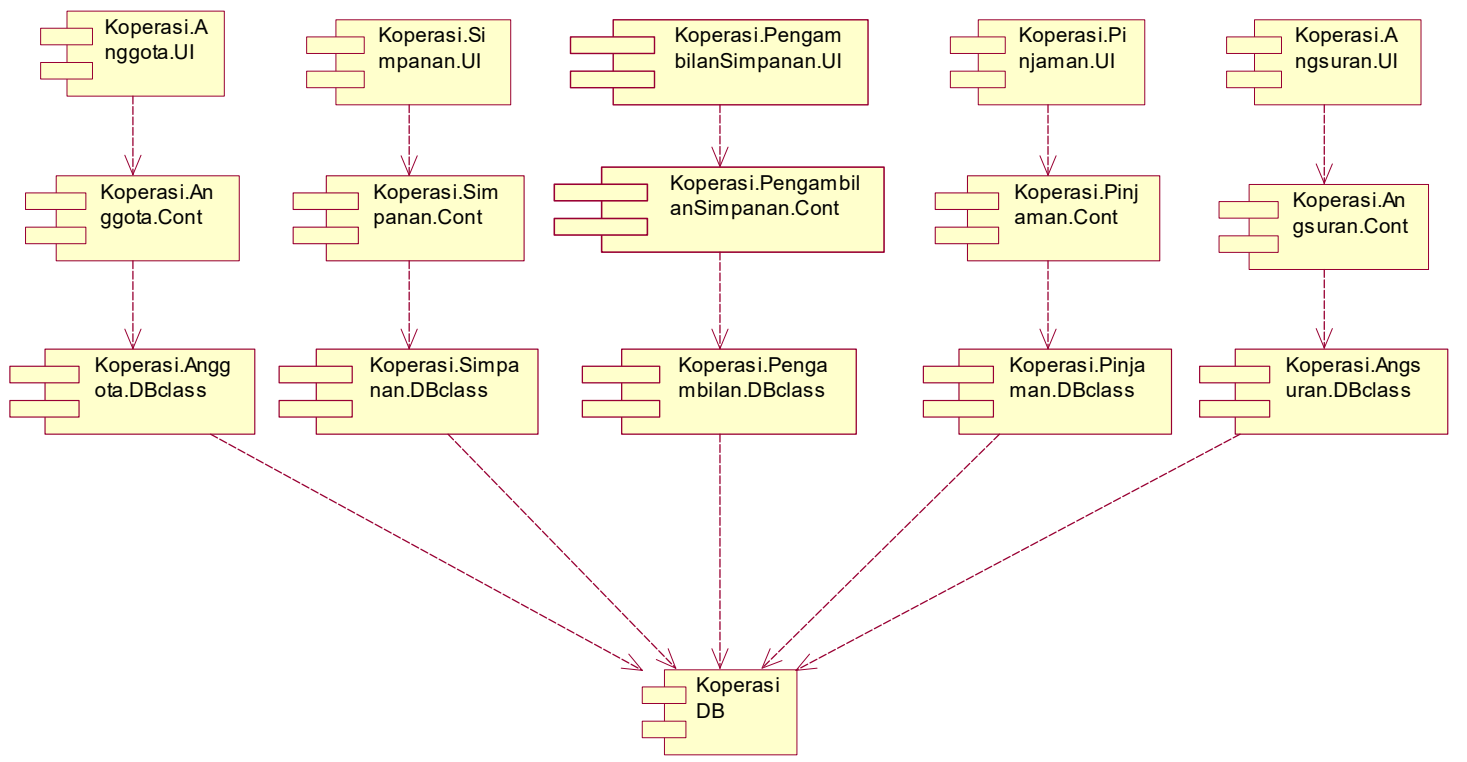

Gambar 11. Desain Komponen Aplikasi Koperas Simpan Pinjam

\subsection{Desain Deployment}

Gambar 12 merupakan desain deployment dari aplikasi yang dibangun. Dimana aplikasi yang dibangun ini menggunakan VisualBasic.Net serta MySql untuk database. 


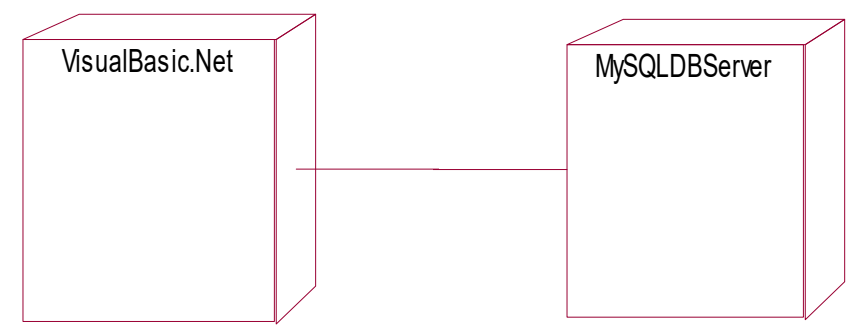

Gambar 12. Desain deployment Aplikasi Koperas Simpan Pinjam

\subsection{Pengujian Aplikasi}

Black-box testing merupakan metode yang digunakan untuk pengujian aplikasi ini. Tujuannya adalah agar fungsi-fungsi yang ada pada aplikasi dapat berjalan dengan baik. Tabel 1 menunjukan hasil pengujian aplikasi.

Tabel 1. Hasil pengujian aplikasi

\begin{tabular}{clc}
\hline No & \multicolumn{1}{c}{ Fungsi } & Status \\
\hline 1 & Anggota melakukan pendaftaran & Valid \\
2 & Input data pada form pendaftaran anggota & Valid \\
3 & Menampilkan informasi setelah melakukan pendaftaran & Valid \\
4 & Login admin & Valid \\
5 & Login menggunakan username dan password yang salah, aplikasi menolak & Valid \\
6 & Logout admin & Valid \\
7 & Input data anggota, setoran, pengambilan, pinjaman serta angsuran & Valid \\
8 & Edit data anggota, setoran, pengambilan, pinjaman serta angsuran & Valid \\
9 & Delete data anggota dan simpanan & Valid \\
& Berhasil melakukan cetak laporan anggota, setoran, pengambilan, pinjaman serta & Valid \\
10 & angsuran & \\
\hline
\end{tabular}

\section{KESIMPULAN}

Berdasarkan hasil pengujian dari rancang bangun aplikasi koperasi simpan pinjam ini bahwa aplikasi ini dapat mengelola data dengan baik, mulai dari data anggota, data setoran, data pengambilan, data peminjaman, data pembayaran cicilan serta dapat menampilkan rekapan data atau laporan, sehingga data-data tersebut menjadi informasi yang bermanfaat. Hal ini sangat membantu kegiatan usaha koperasi simpan pinjam, sehingga meminimalisir human-error serta meningkatkan kinerja koperasi simpan pinjam $\mathrm{ABC}$ karena semua pencatatan transaksi dilakukan melalui aplikasi.

\section{UCAPAN TERIMA KASIH}

Terima kasih disampaikan kepada pihak koperasi simpan pinjam ABC yang telah bersedia memberikan data dan informasi selama proses penelitian.

\section{DAFTAR PUSTAKA}

[1] Rumetna Ms. Pemanfaatan Cloud Computing Pada Dunia Bisnis: Studi Literatur. J Teknol Inf Dan Ilmu Komput [Internet]. 2018;5(3):305-14. Available From: Http://Jtiik.Ub.Ac.Id/Index.Php/Jtiik/Article/View/595

[2] Utami Y, Nugroho A, Wijaya Af. Perencanaan Strategis Sistem Informasi Dan Teknologi Informasi Pada Dinas Perindustrian Dan Tenaga Kerja Kota Salatiga. J Teknol Inf Dan Ilmu Komput. 2018;5(3):253-60.

[3] Yuliansyah S, Masripah S. Sistem Informasi Pencatatan Simpan Pinjam Pada Koperasi. Pilar Nusa Mandiri [Internet]. 2018;14(1):27-34. Available From: Http://Ejournal.Nusamandiri.Ac.Id/Index.Php/Pilar/Article/View/85/71

[4] Pratiwi P, Herliana A. Analisis Dan Desain Sistem Informasi Simpan Pinjam Pada Koperasi Sejahtera Bersama Bandung. J Inform. 2015;2(1):222-30.

[5] Rahma F. Rancang Bangun Sistem Informasi Koperasi Simpan Pinjam Pembiayaan Syariah 
Berbasis Kelompok. J Nas Teknol Dan Sist Inf. 2018;4(1):9-20.

[6] Sakti A, Sutomo E, Sulistiowati S. Rancang Bangun Sistem Pendukung Keputusan Penentuan Kelayakan Pinjaman Nasabah (Studi Kasus Koperasi Ridho Rizki). J Jsika [Internet]. 2014;3(1):144-51. Available From: Http://Jurnal.Stikom.Edu/Index.Php/Jsika/Article/View/329

[7] Wynarti Ia. Pengembangan Permainan Charades Sebagai Media Pembelajaran Materi Jenis-Jenis Bisnis Ritel Kelas Xi Pemasaran Di Smk Negeri 2 Buduran. Pendidik Tata Niaga. 2018;06(03):6370.

[8] Brata Kc, Brata Ah, Yudha Pa. Pengembangan Aplikasi Mobile Augmented Reality Untuk Mendukung Pengenalan Koleksi Museum. J Teknol Inf Dan Ilmu Komput. 2018;5(3):347-52.

[9] Rupilele Fg John. Perancangan Sistem Informasi Manajemen Pelayanan Anggota Jemaat, Baptisan, Dan Pernikahan Berbasis Web (Studi Kasus: Gekari Lembah Pujian Kota Sorong). J Teknol Inf Dan Ilmu Komput. 2018;5(2):147-56.

[10] Zulfikar Ra, Supianto Aa. Rancang Bangun Aplikasi Antrian Poliklinik Berbasis Mobile. J Teknol Inf Dan Ilmu Komput. 2018;5(3):361-70. 